\title{
Deposition of drugs in the nose and sinuses with an exhalation delivery system vs conventional nasal spray or high-volume irrigation in Draf II/III post-surgical anatomy*
}

\author{
Per G. Djupesland', John C. Messina², James N. Palmer³ \\ OptiNose AS, Oslo, Norway \\ 2 OptiNose US, Inc., Yardley, PA, USA \\ ${ }^{3}$ University of Pennsylvania, Perelman School of Medicine, Philadelphia, PA, USA
}

Rhinology 58: 2, 175 - 183, 2020

https://doi.org/10.4193/Rhin18.304

*Received for publication:

December 19, 2018

Accepted: October 21, 2019

\begin{abstract}
Background: Endoscopic sinus surgery is often performed to improve delivery of topical medication into sinus cavities. Intranasal steroids are guideline recommended in post-surgical patients, and experiments with cadavers suggest that surgery improves delivery of drug into sinuses. Exhalation delivery systems (EDS) use a new mechanism for intranasal delivery and have been shown to reach superior/posterior regions of the nasal cavity better than nasal sprays in unoperated patients.
\end{abstract}

Methods: Silicone casts of the nasal cavity and sinuses from a patient after Draf II, and then Draf III, were made from high-resolution computed tomography (CT) data using 3D printing. Internal surfaces were coated with liquid-sensitive, color-changing gel. Color changes were evaluated following conventional nasal spray delivery $(0.1 \mathrm{~mL} \times 2)\left(\right.$ Nasonex $\left.{ }^{\oplus}\right)$, EDS delivery $(0.1 \mathrm{~mL} \times 2)$ $\left(\mathrm{XHANCE}^{\mathrm{TM}}\right)$, and high-volume, low-flow (HVLF) delivery $(\approx 80 \mathrm{~mL})$ with head tilted either $45^{\circ}$ or $90^{\circ}$.

Results: Conventional nasal spray deposited liquid only in anterior nasal segments. EDS deposited liquid throughout the nasal cavity, in surgically opened ethmoid and maxillary spaces, at entrances of the frontal sinuses in Draf II geometry, and into frontal sinuses in Draf III. Tilted $45^{\circ}$, HVLF delivery enters the maxillary sinuses but not the frontal sinuses or the ethmoid region. At full $90^{\circ}$ inclination, HVLF delivery reaches most of the frontal and maxillary sinuses but not the roof and posterior wall of the ethmoid region.

Conclusions: HVLF and EDS produced a deep intranasal/intrasinal deposition in the silicone cast compared with conventional nasal spray delivery; both deposited liquid inside the surgically opened sinuses. HVLF offers the benefit of lavage, whereas EDS may be more efficient and convenient.

Key words: nasal polyps, nasal cavity, paranasal sinuses, nose diseases, nasal mucosa

\section{Introduction}

Chronic rhinosinusitis (CRS) is a chronic inflammatory condition of the nasal cavity and paranasal sinuses. Corticosteroids are a mainstay of medical therapy in the management of CRS, because the broad anti-inflammatory activity addresses the continual production of inflammatory mediators and polyp formation in the nasal passages ${ }^{(1,2)}$. For safety reasons, topically acting corticosteroids are preferred over oral corticosteroids for long-term management, and it is thought to be important to deliver the medication into the affected paranasal sinus cavities to ensure effective long-term management of CRS ${ }^{(1,2)}$. However, due to the complex and convoluted nasal anatomy, unoperated sinuses are difficult to access with medication delivered with high-volume nasal rinses or nasal sprays compared with sinuses that have been surgically opened ${ }^{(2-4)}$.

Endoscopic sinus surgery (ESS) is the standard for surgical treatment of CRS and is generally indicated when symptoms 

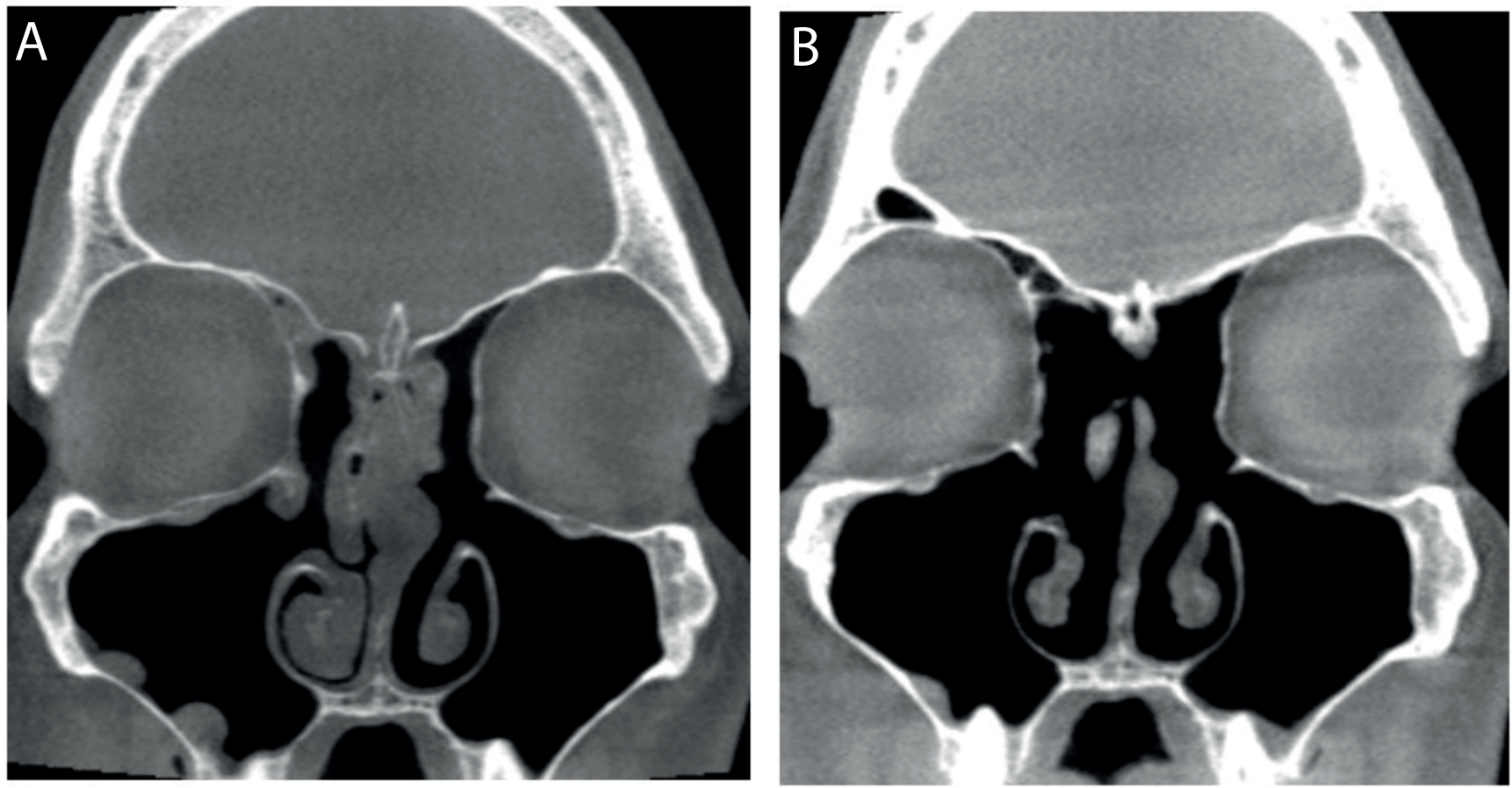

Figure 1. Coronal CT after Draf II (A) and Draf III (B) procedures.

persist despite appropriate medical therapy ${ }^{(2,3)}$. Surgery aims to establish a patent nasal airway and relieve sinus outflow obstruction, decrease the overall inflammatory load, and open the sinuses to allow for removal of debris/bacteria via irrigation and improved postoperative topical drug delivery ${ }^{(3)}$. Surgical approaches can range from dilation of the natural ostia to interventions that completely remodel the anatomy and drainage pathways, particularly aimed at improving access to the paranasal sinuses for delivery of topically acting drugs and for mechanical irrigation ${ }^{(1)}$. In addition to endoscopic maxillary antrostomy and ethmoidectomy, endoscopic frontal sinusotomy, including Draf II and Draf III, is indicated for patients with refractory forms of chronic frontal sinus disease ${ }^{(5)}$. The Draf II procedure involves resection of the floor of the frontal sinus from the nasal septum medially, to the lamina papyracea laterally. The dissection involves removal of the anterior face of the frontal recess. Thus, the frontal sinus ostium is enlarged to its maximum dimension. The Draf III procedure can be easily distinguished from the Draf II procedure by the additional resection of the superior nasal septum and entire frontal sinus floor (Figure 1).

The extent to which a liquid introduced by nasal delivery accesses the sinus cavities after surgery is dependent on a number of factors, including the head position, drug delivery device, and the degree of surgery ${ }^{(3)}$. High-volume, low-flow (HVLF) nasal irrigation (for example, using a squeeze bottle) may be more effective for distributing liquid-containing medication into the sinuses compared with low-volume delivery methods such as nasal sprays, nebulisers, or drops ${ }^{(3,6)}$. There is evidence that sa- line irrigation is beneficial in treating the symptoms of CRS when used as the sole modality of treatment ${ }^{(7)}$. On this background, it has been advocated to add high-dose, topically acting corticosteroids (mainly budesonide) to the HVLF saline nasal irrigation to combine irrigation and drug delivery in post-surgical CRS.

Furthermore, computational fluid dynamics (CFD) simulations of sinus deposition of HVLF-delivered liquid suggest that frontal sinus deposition can be increased after the Draf III procedurebut with substantially reduced maxillary and ethmoid sinus penetration - with the simulations indicating that removal of superior and inter-sinus septa during Draf III unexpectedly causes irrigation fluid to spill prematurely across the resected septum, thus reducing the irrigation of other sinuses ${ }^{(8)}$.

Although the addition of corticosteroid to HVLF rinses conceptually addresses the desire to increase drug delivery to surgically opened sinuses, there is no combination of nasal irrigation with a corticosteroid that is approved by any regulatory agency. There are also drawbacks, including the fact that HVLF rinses with added corticosteroid can be costly, inconvenient, sometimes uncomfortable, require training/education, and can be associated with a number of side effects. These include Eustachian tube dysfunction and local irritation in $\approx 25 \%$ of patients, post-irrigation rhinorrhea, and asymptomatic hypothalamicpituitary-adrenal axis suppression ${ }^{(3,9,10)}$. In addition, with regard to delivery of medication, HVLF devices are generally inefficient, with less than $3 \%$ of the delivered liquid and drug retained in the nasal cavity ${ }^{(4)}$. 


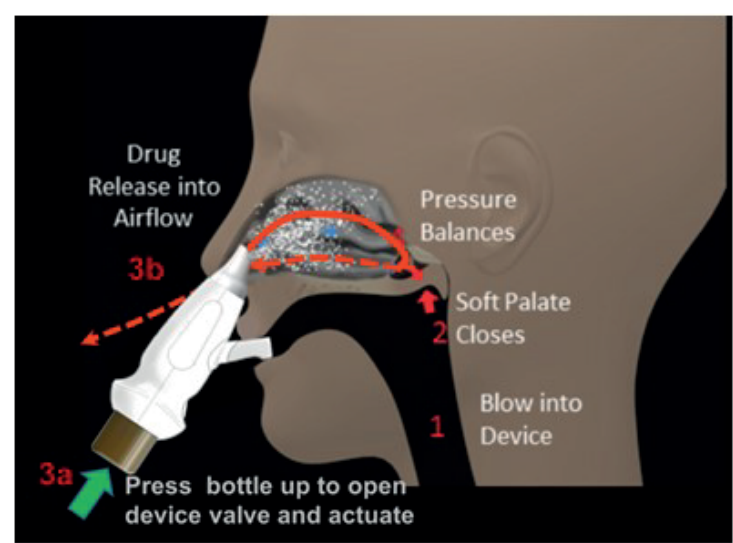

Sagittal plane

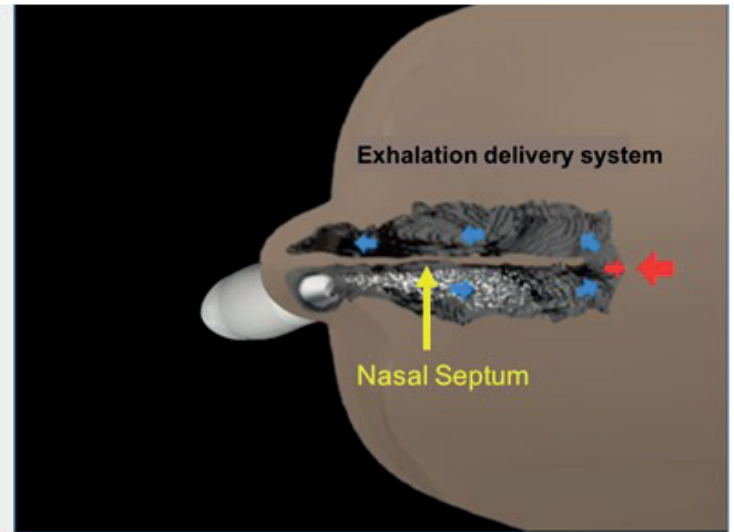

Transverse plane

Figure 2. EDS Mechanism. Source: Palmer et al. EXHANCE-12: 1-year study of the exhalation delivery system with fluticasone (EDS-FLU) in chronic rhinosinusitis. Int Forum Allergy Rhinol. 2018 Jun 1. doi: 10.1002/alr.22141. [Epub ahead of print].

An exhalation delivery system (EDS) with fluticasone XHANCE ${ }^{\oplus}$ (fluticasone propionate) nasal spray, US Food and Drug Administration approved for the treatment of nasal polyps in patients 18 years of age or older, uses an Optinose Exhalation Delivery mechanism for drug delivery that has been demonstrated to improve deposition in the superior and posterior regions of the nasal cavity, including the ostiomeatal complex (OMC) when compared with conventional nasal sprays (Figure 2) (11-14). EDS-FLU, studied in patients with and without prior surgery, has been found to be effective in both sub-populations, raising the interesting question of the degree of sinus deposition that is produced by EDS delivery ${ }^{(15-18)}$. The objective of this study was to assess and compare deposition in anatomically correct postsurgical Draf II and Draf III nasal casts following conventional nasal spray delivery, EDS delivery, and HVLF drug delivery in different head positions (nasal floor horizontal $=0^{\circ}, 45^{\circ}$, or $90^{\circ}$.

\section{Materials and methods}

\section{Cast development}

Two silicone casts of the nasal cavity and sinuses, representing the geometry of a 47-year-old male patient with CRS who had undergone revision ESS of the maxillary, ethmoid, and frontal sinuses, including first a Draf II procedure and a subsequent Draf III procedure, were made from a computed tomography (CT) scan using 3D printing (permission granted by the patient). The CT scan obtained following the Draf III procedure was previously used for CFD simulation of nasal irrigations ${ }^{(8)}$. The DICOM ${ }^{\circledR}$ files of the nasal cavities were loaded into medical image software, Slicer 4.6.2 (Harvard University, Cambridge, MA, US; open source). The software image editor and model maker were used to connect the DICOM files into a 3D geometry to build a model with 3D surfaces representing the nasal cavities. The 3D surface data, derived from hundreds of thousands of small triangles, was exported from Slicer as an STL file. The STL file was imported into the 3D tool software Meshmixer (Autodesk, San Rafael, CA, US), which was used to make a coherent 3D representation of the nasal cavities in preparation for 3D printing. It was necessary to regularise and, in some areas, stitch together the triangles that make the 3D surface; remove artefacts; and remove surfaces that were not related to the nasal cavities. Meshmixer's analysis module was used to ensure that the surface was complete and that the STL could be created into an STL solid file. The STL solid surface was exported as STL (solid) and sent to 3D printing. The nasal geometry was made with a stereolithographic 3D printer (Objet 250; CATI, Buffalo Grove, IL, US). This geometry was placed in a box subsequently filled with a fluid, semitransparent, semisoft silicone (Andersen, Jessheim, Norway). After the silicone had dried, the silicone block was carefully sectioned with a sharp knife and the rigid stereolithographic material representing the air-filled sinonasal geometry was carefully broken into pieces and removed, leaving a transparent silicone replica of the post-surgical sinonasal cavity.

\section{Deposition experiment methods}

Experiments with HVLF in the Draf II and conventional nasal sprays were performed with the nasopharynx patent. The nozzle bottle was inserted tightly into the left nostril of the cast and, with 1 full squeeze of the bottle $(\approx 80 \mathrm{~mL})$, a steady-state liquid level with liquid escaping from the contralateral nostril and/ or the nasopharynx was reached in all HVLF experiments. EDS experiments were performed with a plug inserted in the nasopharynx to simulate velum closure, which occurs naturally during EDS delivery. Velum closure is desirable during HVLF sinonasal irrigations, but it is not always achieved in real-life conditionsas verified by liquid escaping into the oral cavity. In the CFD study using the Draf III geometry, calculations were performed with the velum open ${ }^{(8)}$. A special jig allowed fixation of the cast 


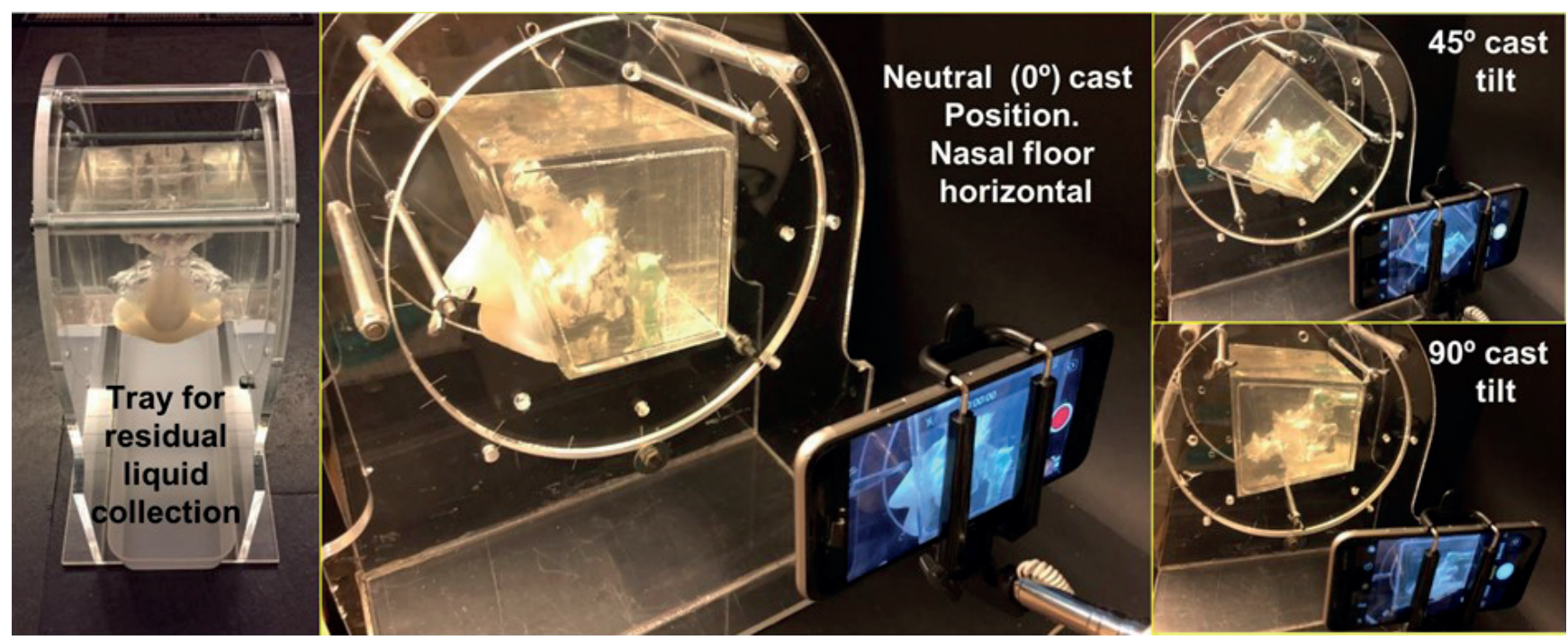

Figure 3. Jig for cast fixation used to set cast at different tilt angles for drug administration.
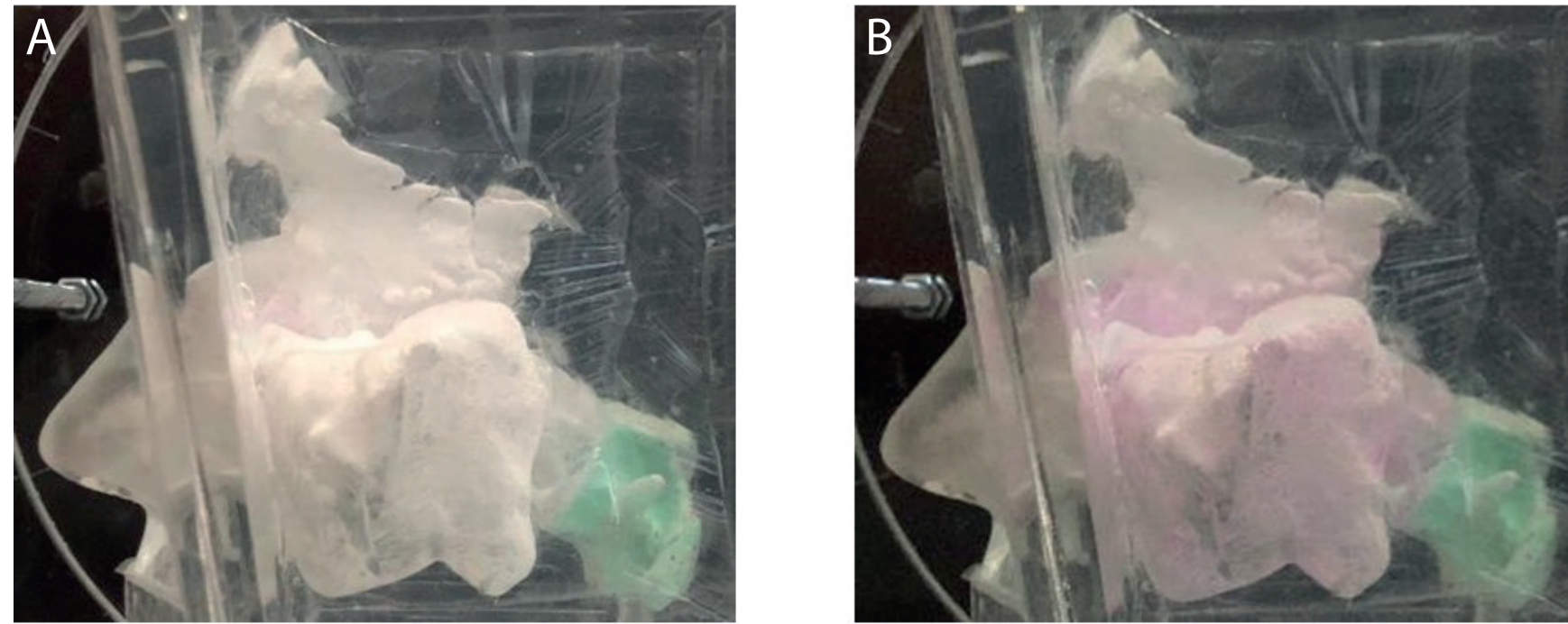

Figure 4. Sar-Gel color change associated with ambient humidity and exhaled breath through empty EDS. A) Sar-Gel-coated cast before exhalation into empty EDS. B) Sar-Gel-coated cast 10 minutes after exhalation into empty EDS.

in standard positions (nasal floor at $0^{\circ}, 45^{\circ}$, and $90^{\circ}$ relative to the horizontal plane). Cast fill and changes in surface color were captured and documented photographically (iPhone 6 or X; Apple, Cupertino, CA, US) (Figure 3).

The internal surfaces of the casts were coated with a sensitive gel that changes color on contact with liquid (Sar-Gel ${ }^{\circledR}$, Sartomer, Exton, PA, US). For HVLF, $\approx 80 \mathrm{~mL}$ was administered to the left side of the cast as was done in the CFD publication, only with inclination of the nasal floor first at $45^{\circ}$ and then at $90^{\circ}(8)$. For the conventional nasal spray condition, 2 sprays $(0.1 \mathrm{~mL}$ each) of a commonly available commercial steroid nasal spray (Nasonex ${ }^{\oplus}$; Merck, Kenilworth, NJ, US) were administered to the left side of the cast. For the EDS administration, 2 sprays $(0.1 \mathrm{~mL}$ each) from the EDS-FLU (XHANCE) were administered to the left nostril of the cast. The specially shaped frustoconical nosepiece was inserted into the nostril to create an airtight seal with the rim of the left nostril of the silicone casts. To allow proper EDSdelivery, the casts were fixed in the jig, a flexible tube $(\approx 100$ $\mathrm{cm}$ long with a 12-mm internal diameter) was connected to the mouthpiece, and the other end inserted into the mouth of the investigator (PD). The investigator took a deep breath, closed the lips around the tube and exhaled into the tube, creating a static positive pressure due to the closed internal valve in the EDS device. When pushing up the bottle of the device while still blowing into the tube, the internal valve opens and pressure is released, creating an airflow synchronously with the actuation of the spray EDS device, carrying particles into the post-surgical geometries. The exhaling procedure lasts for 2-3 seconds, typically resulting in a peak flow of approximately $40 \mathrm{~L} / \mathrm{min}$. 


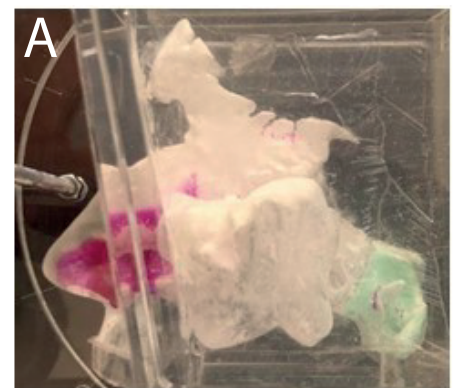

Left lateral

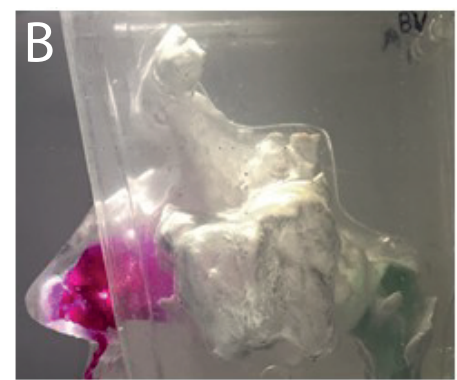

Left lateral

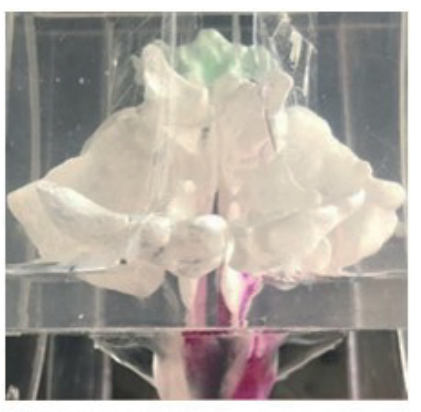

Superior view

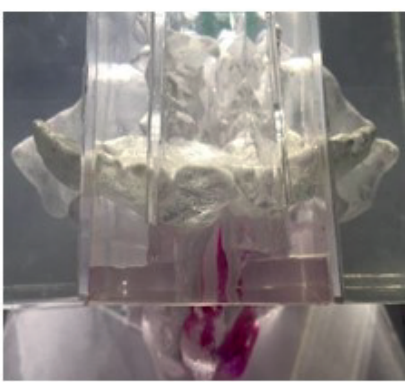

Superior view

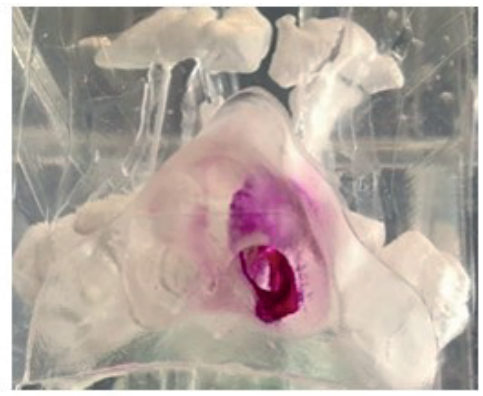

Frontal view

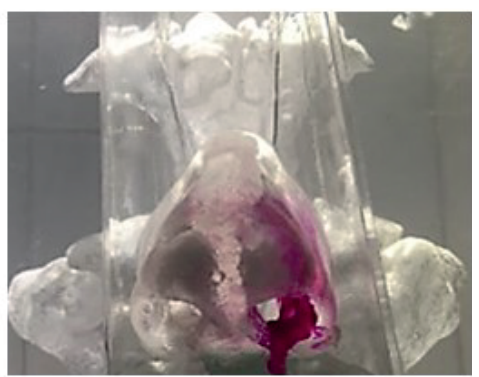

Frontal view

Figure 5. Standard nasal spray (Nasonex ${ }^{\circledast}, 0.1 \mathrm{~mL} \times 2$ \} deposition in Draf II and Draf III casts. A) Deposition of standard nasal spray in Draf II cast after left nostril administration. B) Deposition of standard nasal spray in Draf III cast after left nostril administration.

Previous validation work with nasal sprays and Sar-Gel had shown that the rate of color change is influenced by the time from exposure and volume of liquid reaching the surface ${ }^{(19)}$; therefore, spray and EDS delivery were evaluated at a standardized 10 minutes after administration. The effect of humidity in ambient air and exhaled breath is a potentially confounding variable on the Sar-Gel color change observed during use of an EDS. To visualize and adjust for this effect, experiments were performed under similar ambient conditions using an empty EDS device (2 actuations) in the Draf II cast (Figure 4).

\section{Results}

\section{Cast deposition results}

As expected, conventional intranasal corticosteroid spray deposited liquid only in the anterior nasal segments, with similar deposition profiles in both Draf II and Draf III casts (Figure 5).

HVLF irrigation exhibited different deposition profiles in Draf II and Draf III casts, and head position had a significant effect on which sinuses were exposed to the irrigation liquid (Figure 6). Distribution of HVLF irrigation liquid in the Draf II cast was characterized by penetration of the maxillary sinuses, but not the frontal sinuses or ethmoid region, at a $45^{\circ}$ head position. When the head was tilted at a full $90^{\circ}$, distribution in the Draf II cast increased to include most of the frontal sinus and maxillary sinus, but still did not include the posterior wall of the ethmoid region. HVLF delivery in the Draf III cast at a $45^{\circ}$ head position was characterized by maxillary sinus penetration but no frontal sinus or ethmoid region penetration; when positioned at a $90^{\circ}$ tilt, irrigation liquid was deposited in the frontal sinus; however, there was no distribution to the maxillary sinus or ethmoid region due to the liquid spilling over to the contralateral side of the nose through the region where the nasal septum had been resected.

Distribution with the EDS was generally similar in Draf II and Draf III casts: in both models, liquid deposition was observed throughout the nasal cavity and in the surgically opened ethmoid (including the posterior ethmoid region) and maxillary spaces. Regarding the frontal sinuses, there was limited penetration to the frontal sinus with EDS liquid delivery in the Draf II cast, whereas in the Draf III cast, deposition was observed in the frontal recess and unified frontal sinuses (Figure 7).

\section{Discussion}

Using 3D-printed casts from a CT scan of a patient following Draf II and Draf III procedures, this study demonstrates that both HVLF and EDS produce substantially deeper intranasal deposition compared with conventional spray. This study also identified important distinctions in sinus deposition between EDS and HVLF irrigation. In the Draf II cast, deposition with HVLF irrigation is characterized by penetration into the maxillary sinuses, with increased penetration to the frontal sinuses when head tilt is increased from $45^{\circ}$ to $90^{\circ}$. Liquid delivered by an EDS is also deposited in the maxillary space, as well as in the opened ethmoid (including the posterior ethmoid space), with limited 


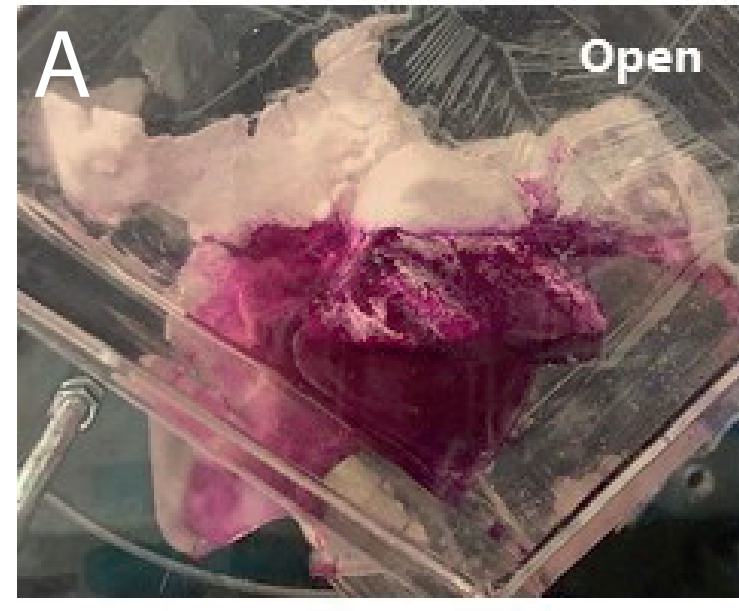

\section{Deposition with $45^{\circ}$ head position}

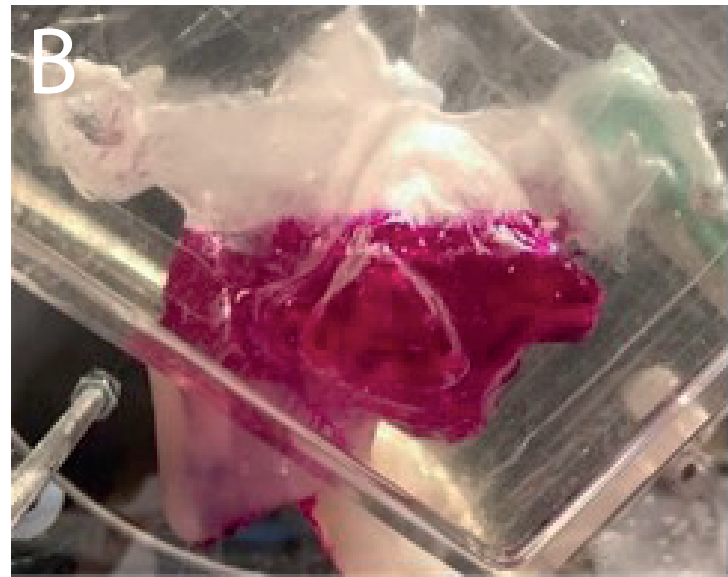

Deposition with $45^{\circ}$ head position
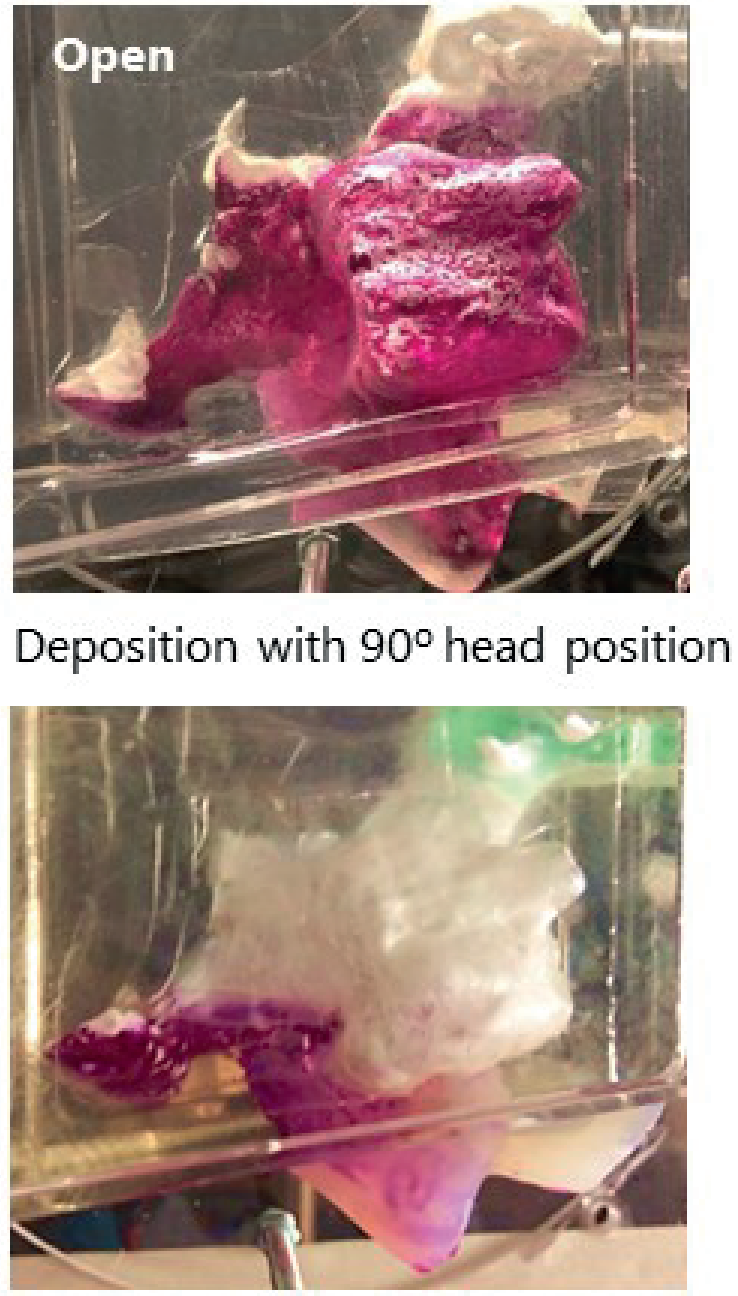

Deposition with $90^{\circ}$ head position

Figure 6. HVLF delivery deposition in Draf II and Draf III using $45^{\circ}$ and $90^{\circ}$ (vertex head positions. A) Deposition of HVLF irrigation in Draf II cast after left nostril administration. B) Deposition of HVLF irrigation in Draf III cast after left nostril administration.

delivery to the frontal sinuses in the Draf II cast. In Draf III postsurgical anatomy, HVLF delivery to the maxillary sinus spaces is actually reduced compared to Draf II anatomy due to the passage of liquid through the resected septum at the $90^{\circ}$ head tilt. HVLF delivery to the frontal sinuses improves with a $90^{\circ}$ head tilt; however, access to the maxillary and ethmoid spaces is reduced. EDS delivery was associated with deposition to the frontal sinuses along with the maxillary and surgically opened ethmoid sinuses in the Draf III cast.

Sinus surgery, recommended for medically refractory CRS patients, is intended to reduce inflammatory burden and to improve access of topically acting corticosteroids into the diseased paranasal sinuses ${ }^{(3)}$. Drug delivery approaches that improve deposition of drug into the sinuses and the sinus drainage pathways, such as irrigations and EDS, may be particularly beneficial for patients who do not experience suffi- cient symptom relief with conventional nasal sprays; however, deposition patterns with alternative delivery methods may be affected by the extent of sinus surgery. The findings of this study are consistent with those of a previously reported CFD study utilizing the same nasal/sinus geometry from which the Draf III cast was derived, suggesting consistency of results across study methods ${ }^{(8)}$. Results following HVLF irrigation demonstrated that increased frontal sinus deposition after Draf III was achieved but, as previously demonstrated with CFD, at the expense of substantially reduced maxillary and ethmoid sinus penetration ${ }^{(8)}$. Although it is typically assumed that more extensive surgery leads to increased sinus penetration with nasal irrigations, these findings support the observations, using CFD in the same geometry, that the resected septum can act as an "escape path", allowing premature exit of irrigated fluid, limiting the potential for mechanical lavage and drug delivery into some sinuses frequently affected by chronic inflammation in CRS. Unlike 


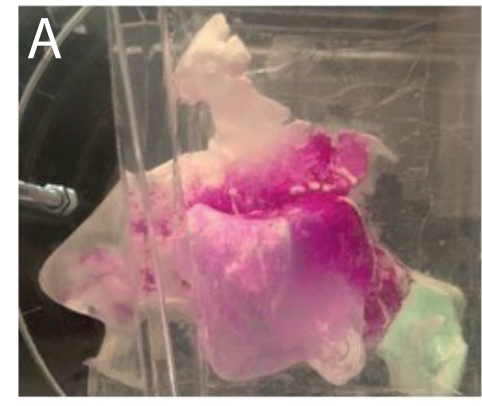

Left lateral

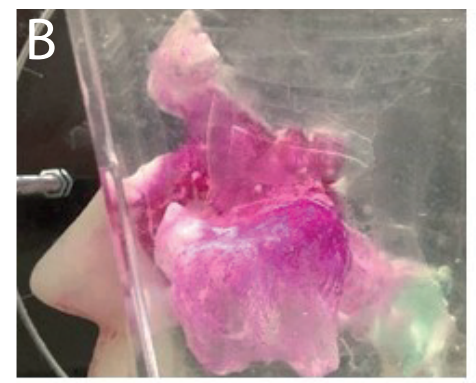

Left lateral

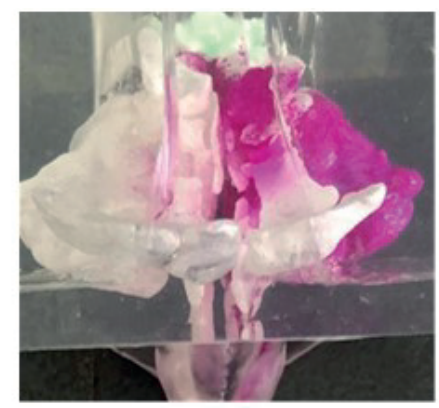

Superior view

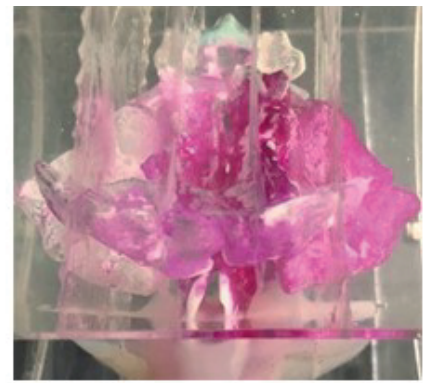

Superior view

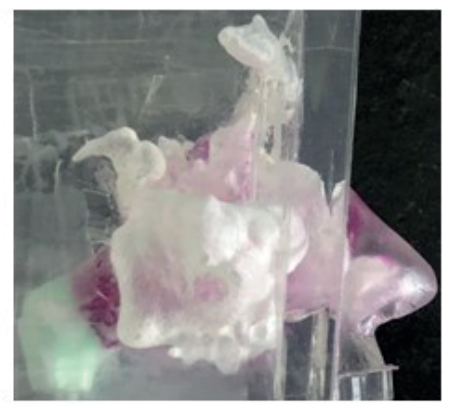

Right lateral

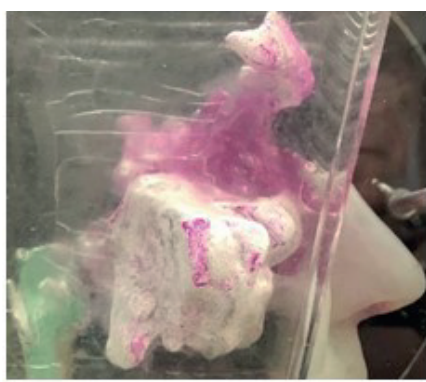

Right lateral

Figure 7. EDS-FLU (0.1 ml x 2 to left nostril\} deposition in Draf II and Draf III casts. A) Deposition of EDS-FLU in Draf II cast after left nostril administration. B) Deposition of EDS-FLU in Draf III cast after left nostril administration.

irrigation delivery, the frontal sinus deposition resulting from EDS delivery does not appear to be negatively affected by the resected septum and may even benefit from the resection as a conduit to the frontal sinuses. With the use of an EDS in the Draf III-operated patient, it is thought that airflow, carrying droplets, enters the opened ethmoid space, primarily turns laterally into the large open maxillary sinuses, and then follows the path of least resistance up into the frontal recess and unified frontal sinuses via the large opening in the septum.

Although HVLF treatment offers a good method for sinonasal irrigation and lavage, it is an inefficient approach to drug delivery due to the small fraction ( $2.5 \pm 1.6 \%$; range, $0 \%-6.6 \%$ ) of fluid retained in the nasal cavity following administration of corticosteroid ${ }^{(4)}$. This implies that, for example, with $1 \mathrm{mg}$ of budesonide diluted in a single administration, one might expect 30 to $40 \mu \mathrm{g}$ to remain in the nose/sinuses, which would be less than the delivered dose of budesonide nasal spray for allergic rhinitis (albeit with a presumably superior pattern of distribution). In contrast, no liquid was observed to escape from the nasal/sinus spaces following drug administration by EDS into nasal casts, indicating that the full dose (372 $\mu \mathrm{g}$ [93 $\mu \mathrm{g}$ per actuation], XHANCE) remains in the nasal passages and sinus cavities. Adjusting for the $1.7 \times$ higher glucocorticoid receptor binding affinity ${ }^{(20)}$ of fluticasone propionate, $372 \mu \mathrm{g}$ is a comparatively high dose in the target region ${ }^{(16,17,21)}$.
In less extensive sinus surgery not involving opening of the frontal sinuses, penetration to the frontal sinuses is expected to be absent or minimal with all methods due to the narrow frontal channels. With enlarged maxillary openings and intact septum, the fraction entering the maxillary sinuses depends heavily on the size of the openings. With HVLF delivery, maxillary sinus penetration may occur, as has been shown by CFD ${ }^{(8)}$, but fluid trapped in the maxillary sinuses may be inconvenient and unacceptable to the patients due to potential issues with delayed drip-out ${ }^{(9)}$. With an intact septum, HVLF delivery can reach all surfaces including the ethmoid region if performed correctly in the $90^{\circ}$ position, but the dose remaining after delivery is expected to be even smaller than in a postsurgical geometry with larger mucosal surfaces ${ }^{(8)}$.

In non-surgical geometries, multiple studies have verified that conventional nasal sprays (Nasonex, Flonase) and nasal pMDIs (QNASL) deposit only in the anterior and lower segment of the nose ${ }^{(22-26)}$. In contrast, previous studies with EDS in both casts and in gamma studies have verified substantial and broad deposition to all mucosal nasal surfaces ${ }^{(27,28)}$ comparing Nasonex and EDS in a normal cast ${ }^{(27,29)}$. The results from the extensive clinical trial program involving hundreds of patients with and without nasal polyps suggest that the enhanced deposition pattern translates into clinically relevant benefits for the patients with and without prior sinus surgery ${ }^{(15-17,30,31)}$. 


\section{Limitations}

One major limitation of this study was that deposition studies were performed in only two post-surgical geometries/casts (after Draf II and Draf III procedures) made from the CT scans from one patient, which may make it difficult to generalize results to patient populations. Variable anatomy, extents of surgery, and irrigation parameters may lead to different degrees of sphenoid sinus penetration by irrigations, and these factors can only be tested methodically with a larger sample size.

Although validation results and findings that are consistent with previously reported studies add to the robustness of these data, there are important limitations of this study that should be considered. One limitation of cast assessment is that the silicone material does not re-create the flexibility of the tissue of the anterior part of the nasal valve region, which may artificially improve deposition in the cast with a conventional nasal spray. This is because the sniffing that many people intuitively or intentionally do during spray delivery tends to narrow, or even collapse, the nasal valve, especially superiorly, due to Bernoulli's principle. Because the cast exhibits less collapsibility in this in vitro model, superior/posterior deposition may be less susceptible to impairment during conventional nasal spray delivery (and less prone to benefit from positive EDS pressure). Although the total amount of drug retained in the nasal passages can be estimated, the quantity and dose reaching specific tissues within the nasal cavity and sinuses cannot be accurately assessed in nasal casts with the Sar-Gel method. Additionally, moisture in external environment and exhaled breath may influence the color-changing Sar-Gel over time. However, validation studies demonstrate minimal spreading outside of the initial deposition area ${ }^{(19)}$, and comparative studies with empty devices under the same conditions support that the color changes observed in this study represent actual drug delivery. Although the nasal casts used in this study are anatomically correct representations of a single individual who underwent Draf II and then Draf III surgical procedures, variations in both nasal anatomy and the detailed nature of the surgical intervention across patients might influence deposition achieved after HVLF or EDS liquid delivery. Additional studies of whether the conclusions of this study may be affected by such variation would be of interest.

\section{Conclusion}

Efficient and effective delivery of drug to the sinuses and to superior and posterior nasal regions is one important goal of sinus surgery. In Draf II- and Draf III-operated anatomy, both HVLF and EDS delivery produce deposition in the sinuses and posterior/superior nasal cavity superior to conventional nasal spray. HVLF delivery was impacted by head position and produced a different deposition pattern in Draf II and Draf III anatomy. EDS delivery produced generally similar deposition patterns in both Draf II- and Draf III-operated anatomy, with liquid deposition in the surgically opened ethmoid and maxillary spaces. There was limited deposition in the frontal sinus spaces in Draf II but observable deposition in Draf III with EDS delivery. The partial septum resection in Draf III resulted in premature loss of liquid with HVLF consistent with findings in CFD simulations. Therefore, while HVLF may offer the benefit of high-volume mechanical lavage in operated patients, EDS offers easy and efficient drug delivery.

\section{Acknowledgements}

Editorial assistance with drafting the report following the authors' guidance, incorporating comments according to authors' feedback, and providing support with submission was provided by ECIR Medical Communications (Cassie Bozeman, PharmD; Medical Director and Benjamin J. Epstein, PharmD; President) funded by OptiNose US.

\section{Authorship contribution}

The sponsor (OptiNose US, Inc.) contributed to the study design, data interpretation, and writing of the report, as well as coordinating the data collection and analysis. PD contributed to study conception and design, acquisition of data, analysis and interpretation of data, drafting of manuscript, and critical revisions. JM contributed to study conception and design, analysis and interpretation of data, drafting of manuscript, and critical revisions. JP contributed to analysis and interpretation of data, drafting of manuscript, and critical revisions.

\section{Conflict of interest}

JM and PD are employees and have stock interest in OptiNose. JP received writing assistance in the preparation of this manuscript, is a consultant for OptiNose, and owns stock in OptiNose.

\section{References}

1. Barham HP, Ramakrishnan VR, Knisely AK, Do TQ, Chan LS, Gunaratne DA, et al. Frontal sinus surgery and sinus distribution of nasal irrigation. Int Forum Allergy Rhinol. 2016;6(3):238-42

2. Fokkens WJ, Lund VJ, Mullol J, et al. European Position Paper on Rhinosinusiti and Nasal Polyps 2012. Rhinol Suppl.
2012;1-298.

3. Orlandi RR, Kingdom TT, Hwang PH, Smith $T L$, Alt JA, Baroody FM, et al. International consensus statement on allergy and rhinology: rhinosinusitis. Int Forum Allergy Rhinol. 2016;6 Suppl 1:S22-209

4. Harvey RJ, Debnath N, Srubiski A, Bleiber B Schlosser RJ. Fluid residuals and drug exposure in nasal irrigation. Otolaryngol Head
Neck Surg. 2009;141(6):757-61

5. Draf W. (2016) Endonasal Frontal Sinus Drainage Type I-III According to Draf. In: Kountakis S, Senior B, Draf W. (eds) The Frontal Sinus. Springer, Berlin, Heidelberg. 2016. DOI https://doi.org/10.1007/978-3662-48523-1_25. ISBN 978-3-662-48521-7.

6. Abadie WM, McMains KC, Weitzel EK. Irrigation penetration of nasal delivery sys- 
tems: a cadaver study. Int Forum Allergy Rhinol. 2011;1:46-9.

7. Chong LY, Head K, Hopkins C, Philpott C, Schilder AG, Burton MJ. Intranasal steroids versus placebo or no interventions for chronic rhinosinusitis. Cochrane Database Syst Rev. 2016;(4):CD011996.

8. Zhao K, Craig JR, Cohen NA, Adappa ND, Khalili S, Palmer JN. Sinus irrigations before and after surgery-visualization through computational fluid dynamics simulations. Laryngoscope. 2016;126(3):E90-6.

9. Kennedy DW. Additional options in chronic rhinosinusitis management. Int Forum Allergy Rhinol. 2018; July 20. doi: 10.1002/ alr.22188. [Epub ahead of print]

10. Soudry E, Wang J, Vaezeafshar R, Katznelson L, Hwang P. Safety analysis of long-term budesonide nasal irrigations in patients with chronic rhinosinusitis post endoscopic sinus surgery. Int Forum Allergy Rhinol. 2016;6(6):568-72.

11. Djupesland PG, Messina J, Mahmoud R. New exhalation delivery systems (EDS) enhance topical steroid delivery in chronic rhinosinusitis with nasal polyps (CSwNP) Poster session presented at: 2017 AAAA Annual Meeting; March 3-6, 2017; Atlanta GA.

12. Djupesland PG, Messina J, Mahmoud R. Enhanced nasal drug delivery with new exhalation delivery systems (EDS). Poster session presented at: 2016 ACAAI Annual Meeting; November 10-14, 2016; San Francisco, CA

13. Djupesland PG. Nasal drug delivery devices: characteristics and performance in a clinical perspective - a review. Drug Deliv Trans Res. 2013;3(1):42-62.

14. Djupesland PG, Zhao K, Messina JC, Mahmoud RA, Palmer JN. Exhalation delivery system provides superior deposition of liquid in post-surgical cavities in comparison to conventional spray or irrigation modalities. Poster session presented at: 2018 ARS at COSM Meeting; April 19-20, 2018; National Harbor, MD.

15. Hansen FS, Djupesland PG, Fokkens WJ. Preliminary efficacy of fluticasone delivered by a novel device in recalcitrant chronic rhinosinusitis. Rhinology. 2010;48(3):292-9.

16. Leopold DA, Elkayam D, Messina JC, KosikGonzalez C, Djupesland PG, Mahmoud RA. NAVIGATE II: Randomized, double-blind trial of the exhalation delivery system with fluticasone (EDS-FLU) for nasal polyposis. J Allergy Clin Immunol. 2019 Jan;143(1):126134.

17. Palmer JN, Jacobson KW, Messina JC, KosikGonzalez C, Djupesland P, Mahmoud RA. EXHANCE-12: 1-year study of the exhalation delivery system with fluticasone (EDS-FLU) in chronic rhinosinusitis. Int Forum Allergy Rhinol. 2018;8(8):869-76.

18. Han JK, Messina JC, Carothers JL, Djupesland PG, Mahmoud RA. EDS-FLU (exhalation delivery system with fluticasone) is effective for nasal polyposis (NP) patients with or without history of prior surgery: Integrated results from NAVIGATE I and II. Poster session presented at: 2018 ARS at COSM Meeting; April 19-20, 2018; National Harbor, MD.

19. Kundoor V, Dalby RN. Assessment of nasal spray deposition pattern in a silicone human nose model using a color-based method. Pharm Res. 2009;27(1):30-36.

20. Daley-Yates PT. Inhaled corticosteroids: Potency, dose equivalence and therapeutic index. Br J Clin Pharmacol. 2015;80(3):372380.

21. Djupesland PG, VIckova I, Hewson G. Impact of baseline nasal polyp size and previous surgery on efficacy of fluticasone delivered with a novel device: a subgroup analysis. Am J Rhinol Allergy. 2010;24(4):291-295.

22. Leach CL, Kuehl PJ, Chand R, McDonald JD. J Aerosol Med Pulm Drug Deliv. 2015;28(5):334-340.

23. Emanuel IA, Blaiss MS, Meltzer EO, Evans P, Connor A. Am J Rhinol Allergy. 2014;28(2):117-121.

24. Shah SA, Berger RL, McDermott J, et al. Regional deposition of mometasone furoate nasal spray suspension in humans. Allergy Asthma Proc. 2015;36(1):48-57.

25. Djupesland PG, Mahmoud RA. Letter to the Editor: Incorrect conclusions regarding dep- osition of conventional mometasone furoate (MF) nasal spray. Allergy Asthma Proc. 2015;36(5):e104.

26. Djupesland PG. Nasal drug delivery devices: characteristics and performance in a clinical perspective-a review. Drug Deliv Transl Res. 2013;3(1):42-62.

27. Djupesland PG, Skretting A. Nasal deposition and clearance in man: comparison of a bidirectional powder device and a traditional liquid spray pump. J Aerosol Med Pulm Drug Deliv. 2012;25(5):280-289.

28. Djupesland PG, Messina J, Mahmoud R. Novel nasal exhalation delivery systems (EDS) may produce beneficial activity independent of delivered drug in inflammatory nasal diseases and migraine via exhaled $\mathrm{CO}_{2}$ and mucosal pH changes. ARS Poster. 2016.

29. Djupesland PG, Skretting A, Winderen $M$, Holand T. Breath actuated device improves delivery to target sites beyond the nasal valve. Laryngoscope. 2006;116(3):466-472.

30. Sindwani R, Han JK, Soteres DF, et al. NAVIGATE I: Randomized, placebo- controlled, double-blind trial of the exhalation delivery system with fluticasone for chronic rhinosinusitis with nasal polyps. Am J Rhinol Allergy. 2018;33(1), 69-82.

31. Sher MR, Steven GC, Romett JL, Pien G, LeBenger K, Messina JC, et al. EXHANCE-3: A cohort study of the exhalation delivery system with fluticasone for chronic sinusitis with or without nasal polyps. Rhinology. 2019 (in press Feb 2020).

Per Djupesland, MD, PhD

OptiNose AS

Norway, Gaustadalléen 21

0349 Oslo

Norway

Tel: +47 21403288

E-mail:

per.djupesland@optinose.com 